\title{
KORELASI TINGKAT PENDIDIKAN DENGAN PARTISIPASI PEMILIH PEMULA DALAM PEMILU NASIONAL SERENTAK 2019 DI KABUPATEN INDRAGIRI HULU
}

\author{
Yusnedi $^{1)}$ Sabrina Utami $^{2)}$ \\ ${ }^{1) 2)}$ Program Studi Manajemen, Sekolah Tinggi Ilmu Ekonomi Indragiri (STIE-I) Rengat \\ Jl. R. Soeprapto No. 14. Rengat | Telp. (0769) 21019| Kode Pos : 29312 | Inhu, Riau \\ ${ }^{1)}$ Email: yusnedi@stieindragiri.ac.id \\ ${ }^{2)}$ Email: sabrinautami@stieindragiri.ac.id \\ Submited: 2019.10.17 Reviewed: 2019.10.24 Accepted: 2019.11.14 \\ https://doi.org/10.34006/jmbi.v8i2.113
}

\begin{abstract}
This research is in Indragiri Hulu Regency, which is specialized in Rengat District. The purpose of this study is to determine how the correlation between the level of education with the participation of novice voters in the 2019 Election in Indragiri Hulu Regency. This research used quantitative methods, with descriptive analysis. The sample in this study were novice voters in Rengat District, Indragiri Hulu Regency, with total 1072 people. By using the Slovin formula, 91 samples were obtained. This research used primary data types. The analytical tool used in this study is by using Simple Linear Regression Analysis with the help of SPSS version 20. The results of this study indicate that the level of education has a correlation with the participation of novice voters in Rengat District, Indragiri Hulu Regency.
\end{abstract}

Keywords: Level Education, Novice Voter Participation, Election

\begin{abstract}
Abstrak
Penelitian ini dilakukan di Kabupaten Indragiri Hulu, yang dikhususkan pada Kecamatan Rengat. Tujuan penelitian ini yaitu untuk mengetahui bagaimana korelasi antara tingkat pendidikan dengan partisipasi pemilih pemula dalam Pemilu Nasional Serentak 2019 di Kabupaten Indragiri Hulu. Penelitian ini menggunakan metode Kuantitatif, dengan analisis deksriptif. Sampel dalam penelitian ini yaitu para pemilih pemula yang ada di Kecamatan Rengat, Kabupaten Indragiri Hulu yang berjumlah 1072 orang. Dengan menggunakan rumus Slovin, maka didapat sample yaitu sebanyak 91 orang. Penelitian ini menggunakan jenis data primer. Alat analisis yang digunakan dalam penelitian ini yaitu dengan menggunakan Analisis Regresi Linear Sederaha dengan bantuan SPSS versi 20. Hasil penelitian ini menunjukkan bahwa tingkat pendidikan memiliki korelasi dengan partisipasi pemilih pemula di Kecamatan Rengat, Kabupaten Indragiri Hulu.
\end{abstract}

Kata Kunci: Tingkat Pendidikan, Partisipasi Pemilih Pemula, Pemilihan Umum

\section{PENDAHULUAN}

Partisipasi politik adalah salah satu aspek penting dalam tatanan demokrasi, sekaligus merupakan ciri khas adanya modernisasi politik. Partisipasi politik juga dilihat sebagai sebuah kegiatan yang dilakukan oleh warga masyarakat untuk ikut terlibat langsung dalam proses pemilihan. Salah satu kegiatan yang menunjukkan adanya bentuk partisipasi politik yang dilakukan oleh warga negara adalah proses pemilihan umum. Pemilu dilihat sebagai sebuah hak warga negara yang sangat principal, karena sebagai sebuah negara demokrasi, maka tentu saja kedaulatan berada di tangan rakyat. Politik sebagai sebuah ilmu memiliki banyak konsep didalamnya, salah satunya yaitu partisipasi politik. Partisipasi politik dinilai sebagai sebuah hal yang sangat penting dalam konteks perpolitikan masyarakat. Hal ini dinilai bahwa dengan warga masyarakat mengikuti partisipasi politik, maka akan terwujud segala hal yang menyangkut kebutuhan warga masyarakat. (Utami, 2018) 
Partisipasi politik merupakan aktivitas masyarakat yang bertujuan untuk mempengaruhi pengambilan keputusan politik. Partisipasi dilakukan orang dalam posisinya sebagai seorang warga negara, partisipasi politik inipun bersifat suka rela dan bukan dimobilisasi oleh negara maupun partai yang berkuasa (Basri, 2011: 97). Masyarakat memiliki hak untuk berpartisipasi dalam politik. Salah satu kelompok pemilih yang saat ini banya menjadi sorotan dalam dunia perpolitikan yaitu tentang pemilih pemula. Pemilih pemula merupakan salah satu persentase yang saat ini paling banyak terdapat di dalam Daftar Pemilih Tetap (DPT). Namun di beberapa waktu belakangan ini, partisipasi pemilih pemula dilihat menurun, sehingga hal ini sangat disayangkan, karena pada dasarnya pemilih pemula inilah harapan untuk kehidupan demokrasi yang akan datang.

Ada beberapa hal yang mempengaruhi kenapa para pemilih pemula tidak mau berpartisipasi dalam kehidupan politik, salah satunya yaitu dilhat dari sisi tingkat pendidkan yang kurang mumpuni yang dienyam oleh para pemilih pemula. Tingkat pendidikan seseorang akan mempengaruhi banyak hal, salah satunya mengenai bagaimana partisipasinya dalam perpolitikan. Dengan adanya tingkat pendidikan masyarakat akan dapat mengembangkan pola pikir dalam menentukan sikap dan pilihannya khususnya dalam kehidupan politik. Tingkat pendidikan dan kecerdasan yang matang akan membuat seseorang dapat lebih memahami setiap pilihan politiknya termasuk dalam melakukan partisipasi politik. Pendidikan memiliki peranan yang sangat penting untuk dapat mengukur kepedulian pemilih dalam menentukan pilihannya terhadap calon yang akan dipilih yang sudah masuk dalam bursa calon tetap. Fakta membuktikan bahwa orang dengan tingkat pendidikan yang tinggi akan cenderung untuk ikut berpartisipasi dalam politik dibandingkan dengan orang yang memiliki tingkat pendidikan yang rendah.

\section{TINJAUAN PUSTAKA DAN HIPOTESIS Tingkat Pendidikan}

Pendidikan dapat didefinisikan sebagai segala sesuatu yang bermanfaat bagi kehidupan manusia, baik terhadap aktivitas jasmaniahnya, pikiran-pikirannya, maupun terhadap ketajaman dan kelembutan hati nuraninya (Shalahuddin, 2011: 19-21). Sedangkan definisi pendidikan menurut Undang-Undang (UU) No. 20 tahun 2003 tentang Sistem Pendidikan Nasional, Pendidikan diartikan sebagai usaha sadar terencana untuk mewujudkan suasana belajar dan proses pembelajaran agar peserta didik secara aktif mengembangkan potensi dirinya untuk memiliki kekuatan spiritual keagamaan, pengendalian diri, kepribadian, kecerdasan, akhlak mulia serta keterampilan yang diperlukan darinya, masyarakat, bangsa, dan negara (Umar Tirtarahardja, 2005: 40-41).

Menurut Dewantara (dalam Hasbullah, 2005:4) "Pendidikan yaitu tuntunan di dalam hidup tumbuhnya anak-anak, adapun maksudnya, pendidikan yaitu menuntun segala kekuatan kodrat yang ada pada anak-anak itu agar mereka sebagai manusia dan sebagai anggota masyarkat dapatlah mencapai keselamatan dan kebahagiaan yang setinggi-tingginya".

Sedangkan menurut Siberman (dalam Sagala 2010: 5), "Pendidikan tidak sama dengan pengajaran karena pengajaran hanya menitikberatkan pada usaha mengembangkan intelektualitas manusia, sedangkan pendidikan berusaha mengembangkan seluruh aspek kepribadian dan kemampuan manusia".

Berdasarkan Undang-Undang Republik Indonesia No. 20 Tahun 2003, jalur pendidikan terdiri dari sebagai berikut:

1. Pendidikan Formal, adalah jalur pendidikan yang terstruktur dan berjenjang yang terdiri atas pendidikan dasar, pendidikan menengah, dan pendidikan tinggi.

2. Pendidikan Non Formal, adalah jalur pendidikan diluar pendidikan formal yang dapat dilaksanakan secara terstrukur dan berjejang

3. Pendidikan Informal, yaitu jalur pendidikan keluarga dan lingkungan 


\section{Partisipasi Politik}

Menurut Budiardjo (2010: 367), "Partisipasi politik adalah kegiatan seseorang atau kelompok orang untuk ikut serta secara aktif dalam kehidupan politik, yakni dengan cara memilih pimpinan negara dan secara langsung atau tidak langsung, mempengaruhi kebijakan pemerintah (public policy)".

Menurut Closky (Yusnedi \& Sabrina, 2019), "Partisipasi politik adalah kegiatankegiatan sukarela dari warga masyarakat melalui mana mereka mengambil bagian dalam proses pemilihan penguasa, dan secara langsung atau tidak langsung, dalam proses pembentukan kebijakan umum"

Menurut Basri (2012: 101), "Partisipasi politik adalah aktivitas warga negara yang bertujuan untuk mempengaruhi pengambilan keputusan politik. Partisipasi politik dilakukan orang dalam posisinya sebagai warga negara, bukan politikus atau pegawai negeri".

(Muslim 2013) menurut Mubyarto (1994:35) partisipasi juga dapat diartikan sebagai keinginan untuk membantu keberhasilan setiap program dimana hal ini tentunya sesuai dengan kemampuan setiap individu tanpa berhenti mengorbankan kepentingan diri sendiri (Davis, dalam Ndraha, 1993: 37). Dari beberapa definisi diatas, maka dapat disimpulkan bahwa partisipasi politik adalah kegiatan seseorang atau kelompok orang untuk ikut serta secara aktif dalam kehidupan politik, antara lain dengan cara memilih pimpinan negara dan secara langsung ataupun tidak langsung, mempengaruhi kebijakan pemerintah.

\section{Model Partisipasi Politik}

Menurut Deth (dalam Basri 2012: 102-103) mengemukakan bahwa model partisipasi politik dibagi menjadi dua bagian besar, yaitu: conventional dan unconventional. Berdasarkan hal ini maka Page (dalam Rahman 2007: 289) memberikan model partisipasi menjadi empat tipe:

- Apabila seseorang memiliki kesadaran politik dan kepercayaan kepada pemerintah tinggi maka partisipasi cenderung aktif

- Kesadaran dan kepercayaan sangat kecil maka partisipasi politik menjadi pasif dan apatis

- Kesadaran politik tinggi tetapi kepercayaan kepada pemerintah lemah, maka perilaku yang muncul adalah militant radikal

- Kesadaran politik rendah tetapi kepercayaan kepada pemerintah tinggi maka partisipasinya menjadi sangat pasif

\section{Pemilih Pemula}

(Afnaniyati 2010) rakyat merupakan subjek politik yang aktif dimana posisi rakyat dapat menentukan berhasil atau tidaknya pemilihan umum. Terdapat beberapa kategori pemilih, dimana salah satunya yaitu pemilih pemula. Pemilih pemula merupakan warga negara Indonesia yang sudah genap berusia 17 tahun atau lebih atau sudah/pernah kawin (Pahmi Sy, 2010: 54). Kemudian dalam pasal 19 ayat (1 dan 2) UU No. 10 tahun 2008 menerangkan bahwa pemilih yang mempunyai hak untuk memilih adalah warga negara Indonesia yang didaftar oleh penyelenggara pemilu dalam daftar pemilih dan pada hari pemungutan suara telah berusia genap 17 tahun atau lebih atau sudah/pernah menikah (Kartikatantri, Hafiar, dan Priyatna, 2015). Pemilih pemula merupakan pemilih yang baru pertama kali memilih karena usia mereka baru saja memasuki usia pemilih yaitu 17 hingga 21 tahun. Pengetahuan mereka terhadap pemilu tidak tidak berbeda jauh dengan kelompok lainnya, dimana yang menjadi pembeda adalah soal antusiasme dan preferensi.

Pemilih pemula khususnya remaja (berusia 17 tahun) mempunyai nilai kebudayaan yang santai, bebas, dan cenderung pada hal-hal yang informal dan mencari kesenangan, oleh karena itu semua hal yang kurang menyenangkan akan dihindari. Disamping mencari kesenangan, kelompok sebaya adalah paling penting dalam kehidupan seorang remaja, 
sehingga bagi seorang remaja perlu mempunyai kelompok teman sendiri dalam pergaulan (Suhartono, 2009: 6).

\section{Pemilihan Umum Serentak}

Secara konsep, pemilu serentak merupakan penggabungan pemilu legislatif dan pemilu eksekutif dalam satu hari pemilihan. Mark P Jones mengemukakan bahwa pemilihan umum dikatakan serentak jika pemilihan presiden putaran pertama atau satu-satunya putaran dalam pemilihan presiden dilaksanakan di hari yang sama dengan pemilihan anggota legislatif. Pemilu serentak (Concurrent Election) secara sederhana dapat didefinisikan sebagai sistem pemilu yang melangsungkan beberapa pemilihan pada satu waktu secara bersaman (Haris et al, 2014).

\section{State of The Art (Penelitian Terdahulu)}

Penelitian tentang pemilu serta partisipasi politik bukanlah sebuah penelitian yang baru, sudah banyak peneliti yang juga membahas mengenai hal ini, seperti Guntur Ardian Tamara dimana dalam peelitiannya yaitu melihat mengenai bagaimana pengaruh status sosial ekonomi terhadap partisipasi politik dalam pemilihan Kepala Daerah Kabupaten Lampung Selatan tahun 2015, hasil penelitiannya yaitu bahwa status sosial ekonomi memiliki pengaruh terhadap partisipasi masyarakat. Penelitian lainnya yaitu dari Hardiman Wirathama, dimana penelitiannya melihat bagaimana tingkat partisipasi politik ditinjau dari status sosial ekonomi di Kelurahan Tamangapa Kecamatan Mangala, Makassar, hasil penelitiannya yaitu status sosial ekonomi yang rendah menjadi salah satu penyebab rendahnya partisipasi politik. Selain kedua penelitian tersebut, penelitian dari Asrobi Panuntun juga membahas hal yang serupa, dimana penelitiannya melihat bagaimana hubungan pendidikan terhadap partisipasi politik masyarakat dalam pemilu presiden 2014 di Kelurahan Baqa Kecamatan Samarinda Seberang Kota Samarinda, hasil penelitiannya yaitu bahwa pendidikan memiliki hubungan yang kuat terhadap partisipasi politik masyarakat. Sedikit berbeda dengan penelitian-penelitian sebelumnya yang melihat tentang partisipasi masyarakat secara umum, penelitian ini lebih mengkhususkan kepada partisipasi para pemilih pemula. Adapun hal yang akan diteliti lebih lanjut yaitu mengenai bagaimana korelasi tingkat pendidikan dengan partisipasi pemilih pemula dalam pemilu nasional serentak 2019 di Kabupaten Indragiri Hulu.

\section{HIPOTESIS PENELITIAN}

Adapun hipotesis dalam penelitian ini yaitu:

"Diduga bahwa tingkat pendidikan memiliki korelasi terhadap partisipasi pemilih pemula pada Pemilihan Umum Nasional serentak 2019 di Kabupaten Indragiri Hulu.”

\section{METODE PENELITIAN}

Penelitian ini dilakukan di Kabupaten Indragiri Hulu dengan pendekatan kuantitatif. Penelitian ini termasuk jenis penelitian deskriptif, menurut Arikunto (2010: 234), menjelaskan bahwa penelitian deskriptif adalah suatu bentuk penelitian yang paling besar ditunjukkan untuk menggambarkan kejadian-kejadian yang ada.

Populasi dan sampel dalam penelitian ini adalah pemilih pemula yang ada di Kabupaten Indragiri Hulu, khususnya di Kecamatan Rengat. Adapun jumlah populasi dalam penelitian ini yaitu sebanyak 1072 orang, dengan menggunakan rumus Slovin, maka didapat sampel penelitian sebanyak 91 orang. Teknik pengambilan sampel yang digunakan yaitu menggunakan menggunakan multistage random sampling, dimana hal ini merupakan pengembangan dari random cluster (Eriyanto, 2007: 139). Multistage Random Sampling ini juga menggunakan berbagai metode random sampling secara bersama-sama dengan seefisien dan seefektif mungkin. Dalam penelitian ini terdapat dua variabel yaitu tingkat pendidikan sebagau variabel $\mathrm{X}$ dan partisipasi pemilih pemula sebagai variabel $\mathrm{Y}$. untuk proses 
pengambilan data yaitu dilakukan dengan menyebarkan kuesioner yang nantinya akan diisi secara langsung oleh sampel dalam penelitian ini.

\section{HASIL DAN PEMBAHASAN}

\section{Uji Instrumen}

\section{Uji Validitas}

Untuk menentukan instrumen valid atau tidak adalah dengan ketentuan sebagai berikut:

Jika $r_{\text {hitung }}>r_{\text {tabel }}$ dengan taraf signifikansi 0,05, maka instrumen tersebut dikatakan valid.

Jika $\mathrm{r}_{\text {hitung }}<\mathrm{r}_{\text {tabel }}$ dengan taraf sigifikansi 0,05, maka instrumen tersebut dikatakan tidak valid

Adapun Uji Validitas untuk variabel $\mathrm{X}_{1}$ (Tingkat Pendidikan), dan $\mathrm{Y}$ (Partisipasi Politik Pemilih Pemula) dapat dilihat pada tabel berikut:

Tabel : Uji Validitas (X) Tingkat Pendidikan

\begin{tabular}{|l|l|l|l|}
\hline Item & $\begin{array}{l}\text { Corrected Item Total } \\
\text { Correlation }\end{array}$ & $\mathrm{r}_{\text {tabel }}$ & $\begin{array}{l}\text { Valid/Tidak } \\
\text { Valid }\end{array}$ \\
\hline P1 & 0,810 & 0,207 & Valid \\
\hline P2 & 0,848 & 0,207 & Valid \\
\hline P3 & 0,830 & 0,207 & Valid \\
\hline P4 & 0,879 & 0,207 & Valid \\
\hline P5 & 0,810 & 0,207 & Valid \\
\hline
\end{tabular}

Tabel : Uji Validitas (Y) Partisipasi Politik Pemilih Pemula

\begin{tabular}{|l|l|l|l|}
\hline Item & $\begin{array}{l}\text { Corrected Item Total } \\
\text { Correlation }\end{array}$ & $\mathrm{r}_{\text {tabel }}$ & $\begin{array}{l}\text { Valid/Tidak } \\
\text { Valid }\end{array}$ \\
\hline P1 & 0,562 & 0,207 & Valid \\
\hline P2 & 0,813 & 0,207 & Valid \\
\hline P3 & 0,754 & 0,207 & Valid \\
\hline P4 & 0,826 & 0,207 & Valid \\
\hline P5 & 0,815 & 0,207 & Valid \\
\hline
\end{tabular}

Sumber: Data Olahan SPSS Versi 20

\section{Uji Reliabilitas}

Adapun hasil perhitungan reliabilitas variabel $\mathrm{X}$ dan variabel $\mathrm{Y}$ adalah sebagai berikut:

Tabel 32: Uji Reliabilitas (Y) Partisipasi Politik Pemilih Pemula

Reliability Statistics

\begin{tabular}{|l|l|}
\hline Cronbach's Alpha & Nof Items \\
\hline .888 & 5 \\
\hline
\end{tabular}

Sumber: Data Olahan SPSS Versi 20

Dengan menggunakan rumus Cronbach's Alpha diperoleh hasil perhitungan reliabilitas Pendidikan (X) pada tingkat kepercayaan yang baik yaitu 0,888 lebih besar dari pada 0,207, maka dapat disimpulkan bahwa alat ukur untuk Pendidikan $(\mathrm{X})$ dalam penelitian ini adalah reliabel. 
Reliability Statistics

\begin{tabular}{|l|l|}
\hline Cronbach's Alpha & Nof Items \\
\hline 814 & 5 \\
\hline
\end{tabular}

Sumber: Data Olahan SPSS Versi 20

Dengan menggunakan rumus Cronbach's Alpha diperoleh hasil perhitungan reliabilitas Partisipasi Politik Pemilih Pemula (Y) pada tingkat kepercayaan yang baik yaitu 0,814 lebih besar dari pada 0,207, maka dapat disimpulkan bahwa alat ukur untuk Partisipasi Politik Pemilih Pemula (Y) dalam penelitian ini adalah reliabel.

\section{Analissis Regresi Sederhana (Deskritif Statistik)}

Coefficients $^{\mathrm{a}}$

\begin{tabular}{|c|c|c|c|c|c|c|}
\hline \multirow{2}{*}{\multicolumn{2}{|c|}{ Model }} & \multicolumn{2}{|c|}{$\begin{array}{l}\text { Unstandardized } \\
\text { Coefficients }\end{array}$} & \multirow{2}{*}{$\begin{array}{l}\text { Standardized } \\
\text { Coefficients } \\
\text { Beta }\end{array}$} & \multirow[b]{2}{*}{ t } & \multirow[b]{2}{*}{ Sig. } \\
\hline & & $\mathrm{B}$ & Std. Error & & & \\
\hline & (Constant) & 5.771 & .703 & & 8.204 & .000 \\
\hline & $\begin{array}{l}\text { Tingkat } \\
\text { Pendidikan }\end{array}$ & .733 & .061 & .788 & 12.093 & .000 \\
\hline
\end{tabular}

a. Dependent Variable: Partisipasi Politik Pemilih Pemula

Berdasarkan data SPSS Versi 22 diketahui bahwa konstanta (a) adalah 5,771 dan koefisien $\mathrm{X}_{1}$ $\left(b_{1}\right)$ adalah 0,733 dengan persamaan regresi liner sederhana adalah $Y=5,771+0,733 X_{1}$

$\mathrm{a}=$ konstanta sebesar 5,771 dan jika variabel independen dianggap nol (0) artinya Partisipasi Politik Pemilih Pemula adalah sebesar 5,771 apabila $\mathrm{X}_{1}$ (Tingkat Pendidikan) sama dengan 0 (nol).

$\mathrm{b}_{1}=$ koefisien regresi Tingkat Pengetahuan sebesar 0,733 menunjukkan bahwa setiap peningkatan Tingkat Pendidikan sebesar satu satuan maka akan terjadi peningkatan Partisipasi Pemilih Pemula sebesar 0,733.

\section{Analisis Korelasi Sederhana (R) dan Keofisien Determinasi $\left(\mathbf{R}^{\mathbf{2}}\right)$}

Model Summary ${ }^{\mathrm{b}}$

\begin{tabular}{|l|l|l|l|l|}
\hline Model & $\mathrm{R}$ & R Square & $\begin{array}{l}\text { Adjusted R } \\
\text { Square }\end{array}$ & $\begin{array}{l}\text { Std. Error of } \\
\text { the Estimate }\end{array}$ \\
\hline 1 & $.788^{\mathrm{a}}$ & .622 & .617 & 2.07097 \\
\hline
\end{tabular}

a. Predictors: (Constant), Tingkat Pendidikan

b. Dependent Variable: Partisipasi Politik Pemilih Pemula

Pada tabel di atas diketahui bahwa $\left(\mathrm{X}_{1}\right)$ Tingkat Pendidikan mempunyai hubungan dengan (Y) Partisipasi Politik Pemilih Pemula. Hal ini dapat dilihat dari nilai koefisien korelasi $\mathrm{R}$ adalah 0,788 artinya memiliki hubungan yang kuat. dan selanjutnya diuji dengan Koefisien determinasi $\left(\mathrm{R}^{2}\right)$ adalah 0,622 . hal ini menunjukkan bahwa $\left(\mathrm{X}_{1}\right)$ Tingkat Pendidikan dapat memberikan sumbangan terhadap variabel (Y) Partisipasi Politik Pemilih Pemula sebesar 62,2 $\%$. Dan sisanya $37,8 \%$ di pengaruhi oleh variabel lain yang tidak diteliti dalam penelitian ini. 


\section{Analisis Hipotesis}

Uji Hipotesis secara simultan (Uji Hipotesis dengan Uji "F")

ANOVA $^{\mathrm{a}}$

\begin{tabular}{|l|l|l|l|l|l|}
\hline Model & $\begin{array}{l}\text { Sum of } \\
\text { Squares }\end{array}$ & df & Mean Square & F & Sig. \\
\hline Regression & 627.226 & 1 & 627.226 & 146.243 & $.000^{\mathrm{b}}$ \\
Residual & 381.714 & 89 & 4.289 & & \\
Total & 1008.939 & 90 & & & \\
\hline
\end{tabular}

a. Dependent Variable: Partisipasi Politik Pemilih Pemula

b. Predictors: (Constant), Tingkat Pendidikan

Dari tabel diatas dapat dilihat $\mathrm{F}$ hitung yaitu 146,243 sedangkan F tabel dapat diperoleh dengan menggunakan tabel $\mathrm{F}$ dengan derajat bebas (df) residual (sisa) yaitu 89 sebagai df penyebut dan df Regresion (perlakuan) yaitu 2 sebagai df pembilang dengan taraf signifikan 0,05, sehingga diperoleh $\mathrm{F}$ tabel 3,10. karena $\mathrm{F}$ hitung $(146,243)>\mathrm{F}$ tabel $(3,10)$ maka Ho ditolak dan Ha diterima. Artinya variabel Tingkat Pendidikan memiliki pengaruh signifikan terhadap Partisipasi Politik Pemilih Pemula pada Kecamatan Rengat Kabupaten Indragiri Hulu

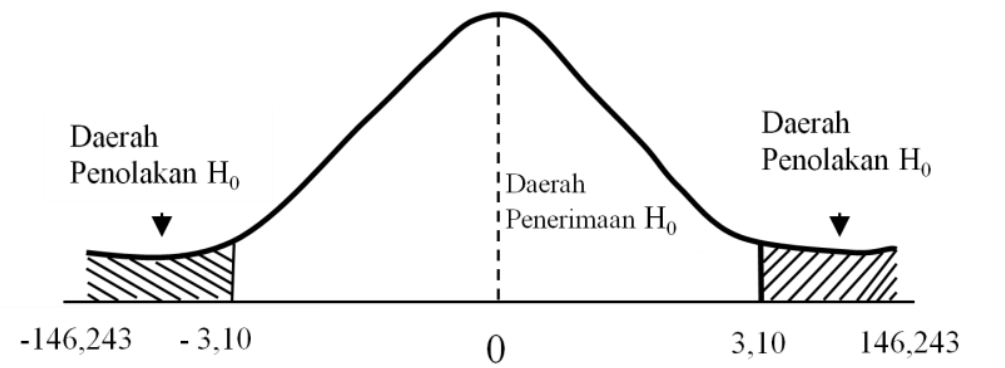

Gambar 3 : Kurva Normal Uji F

\section{PENUTUP}

Hasil pengujian persamaan regresi liner sederhana menunjukan bahwa variabel independen Tingkat Pendidikan berpengaruh terhadap variabel dependent Partisipasi Politik Pemilih Pemula. Adapun interprestasi hasil penelitian ini adalah sebagai berikut :

Diperoleh nilai konstanta sebesar 5,771 dan jika variabel independen dianggap nol (0) maka Partisipasi Politik Pemilih Pemula dengan 5,771 artinya Partisipasi Politik Pemilih Pemula adalah sebesar 5,771 apabila X1 (Tingkat Pendidikan) sama dengan 0 (nol). b1 = koefisien regresi Tingkat Pendidikan sebesar 0,733 menunjukkan bahwa setiap peningkatan Tingkat Pendidikan sebesar satu satuan maka akan terjadi peningkatan Partisipasi Politik Masyarakat sebesar 0,733 .

Nilai koefisien korelasi diketahui bahwa (X1) Tingkat Pendidikan mempunyai hubungan dengan (Y) Partisipasi Politik Pemilih Pemula Hal ini dapat dilihat dari nilai koefisien korelasi sederhana $\mathrm{R}$ adalah 0,788 artinya memiliki hubungan yang kuat serta searah. dan selanjutnya diuji dengan Koefisien determinasi sederhana (R2) adalah 0,622. hal ini menunjukkan bahwa (X1) Tingkat Pendidikan dapat memberikan sumbangan terhadap variabel (Y) Partisipasi Politik Pemilih Pemula sebesar 62,2 \%,dan sisanya 37,8 \% di pengaruhi oleh variabel lain yang tidak diteliti dalam penelitian ini. 
Dari hasil perhitungan di peroleh $\mathrm{F}$ hitung yaitu 146,243 sedangkan $\mathrm{F}$ tabel dapat diperoleh dengan menggunakan tabel $\mathrm{F}$ dengan derajat bebas (df) residual (sisa) yaitu 89 sebagai df penyebut dan df Regresion (perlakuan) yaitu 2 sebagai df pembilang dengan taraf signifikan 0,05, sehingga diperoleh $F$ tabel 3,06. karena $F$ hitung $(146,243)>F$ tabel $(3,10)$ maka Ho ditolak dan Ha diterima. Artinya variabel Tingkat Pendidikan memiliki pengaruh signifikan terhadap Partisipasi Politik Pemilih Pemula pada Kecamatan Rengat, Kabupaten Indragiri Hulu.

\section{REFERENCE}

Afnaniyati, Mir'aatunnisa. 2010. "Pengaruh Tingkat Pendidikan Pemilih Pemula Terhadap Angka Golput Pada Pilkada Lamongan 2010 Di Kec. Kedungpring, Kab. Lamongan" 02: 2010

Akdon dan Riduwan. 2005. Rumus dan Data dalam Aplikasi Statistik. Bandung: Alfabeta

Arikunto, S. 2010. Prosedur Penelitian Suatu Pendekatan Praktik. Jakarta: Rineka Cipta

Basri Seta. 2012. Pengantar Ilmu Politik. Jogjakarta: Indie Book Corner

Budiradjo, Miriam. Dasar-Dasar Ilmu Politik. Jakarta: PT. Gramedia Pustaka Utama

Haris, Syamsudin, Ramlan Surbakti, Sri Nuryanti, and Ikrar Nusa Bhakti. 2014. "Pemilu Nasional Serentak 2019.” : 1-31

Habsullah. 2006. Dasar-Dasar Ilmu Pendidikan. Jakarta: PT. Raja Grafindo Persada

Kartikatantri, Almira Ditrya, Hanny Hafiar, and Centurion C Priyatna. 2015. "Perbedaan Sikap Pemilih Pemula Antara Peserta Dan Bukan Peserta 'Roadshow Pendidikan Pemilu"”. Jurnal Komunikasi 7/1: 26-40

Muslim, Agus. 2013. "Faktor-Faktor Partisipasi Politik Pemilih Pemula Di Kecamatan Andir Pada Pemilihan Gubernur Dan Wakil Gubernur (PILGUB) Jabar 2013." (http//elib.unikom.ac.id/files/disk1/639/jbptunikompp-gdl-agusmuslim-31913-11artikel-pdf)

Panuntun, Asrobi. 2015. "Hubungan Pendidikan terhadap Partisipasi Politik Masyarakat dalam Pemilu Presiden 2014 di Kelurahan Baqa Kecamatan Samarinda Seberang Kota Samarinda”. e-Journal Administrasi Negara, 3 (2) 2015: 743-753 (http://ejournal.an.fisip-unmul.org)

Prof. Umar Tirtarahardja, S. L. La Sulo. 2005. Pengantar Pendidikan. Jakarta: PT. Rineka Cipta

Rahman, A. 2007. Sistem Politik Indonesia. Yogyakarta: Graha Ilmu

Sagala, Syaiful. 2010. Konsep dan Makna Pembelajaran. Bandung: Alfabeta

Sekretariat Jenderal KPU Biro Teknis dan Hupmas. 2010. Modul: Pemilu untuk Pemula. Jakarta: Penerbit Komisi Pemilihan Umum

Shalahuddin, M dan Rosa, A. S. 2011. Modul Pembelajaran Rekayasa Perangkat Lunak (Terstruktur dan Berorientasi Objek). Bandung: Modula

Suhartono. 2009. Tingkat Kesadaran Politik Pemilih Pemula dalam Pilkada: Suatu Refleksi School-Based Democracy Education (Studi Kasus Pilkada Provinsi Banten, Jawa Barat). Hasil Penelitian Pascasarjana UPI

Suryadi, Budi. 2007. Sosiologi Politik Sejarah Definisi dan Perkembangan Konsep. Jogjakarta: IRCiSoD

Sy, Pahmi. 2010. Politik Pencitraan. Jakarta: Gaung Persada Press 
Tamara, Ardyan Guntur. 2016. "Pengaruh Status Sosial Ekonomi Terhadap Partisipasi Politik Masyarakat dalam Pemilihan Kepala Daerah Kabupaten Lampung Selatan Tahun 2015 (Studi Perbandingan Kelurahan Way Urang dan Kelurahan Bumi Agung, Kecamatan Kalianda Kabupaten Lampung Selatan”. (http://digilib.unila.ac.id)

Undang-Undang Republik Indonesia No. 20 Tahun 2003

Utami, S. (2018). Korelasi Tingkat Pengetahuan Dan Pendidikan Terhadap Partisipasi Politik Masyarakat Pada Pemilihan Gubernur Riau 2018 Di Kecamatan Rengat. Jurnal Manajemen Dan Bisnis, 7(4), 35-45. https://doi.org/10.34006/jmb.v7i4.20

Yusnedi, \& Sabrina, U. (2019). ANALISIS BUDAYA POLITIK LOKAL DAN PARTISIPASI POLITIK DALAM PELAKSANAAN PEMILIHAN UMUM 2019 DI DESA KOTA LAMA, KECAMATAN RENGAT BARAT. Jurnal Manajemen Dan Bisnis, VIII(01), 229-236. https://doi.org/10.1017/CBO9781107415324.004

Wirahmat, Hardiman. 2013. “Analisis Tingkat Partisipasi Politik Ditinjau Dari Status Sosial Ekonomi: Studi Lapangan Kelurahan Tamangapa Kecamatan Manggala Kota Makassar". (http://repositori.uin-alauddin.ac.id) 